\title{
Progesterone Receptor Expression in the Developing Mesocortical Dopamine Pathway: Importance for Complex Cognitive Behavior in Adulthood
}

\author{
Jari Willing ${ }^{\mathrm{a}-\mathrm{c}}$ Christine K. Wagner ${ }^{\mathrm{a}, \mathrm{b}}$ \\ ${ }^{a}$ Department of Psychology, and ${ }^{b}$ Center for Neuroscience Research, University at Albany, SUNY, Albany, N.Y., \\ and 'Behavioral Neuroscience Division, Department of Psychology, University of Illinois at Urbana-Champaign, \\ Champaign, III., USA
}

\section{Key Words}

Progesterone receptor - Dopamine - Development .

Cognitive flexibility

\begin{abstract}
Background: Numerous psychiatric and behavioral disorders such as autism, attention deficit disorder and schizophrenia may involve disruptions in the development of the mesocortical dopamine pathway, consisting of dopaminergic projections from the midbrain ventral tegmental area (VTA) to the medial prefrontal cortex (mPFC). Nuclear steroid hormone receptors are powerful transcription factors and can profoundly and permanently alter fundamental processes of neural development. Nuclear progesterone receptor (PR) is transiently expressed in both the VTA and the PFC of rodents during perinatal life, suggesting that PR may regulate the normal development of this important behavioral circuit. Methods and Results: Here, we demonstrate that virtually all PR-immunoreactive (PR-ir) cells in the VTA also express tyrosine hydroxylase immunoreactivity ( $\mathrm{TH}$-ir). In addition, retrograde tract tracing reveals that many PR-ir cells in the VTA project to the MPFC. Administration of a PR antago-
\end{abstract}

nist to rats during the neonatal period decreased TH-ir fiber density in the prelimbic mPFC of juveniles (postnatal day 25) and decreased levels of TH-ir in the VTA of adults. Neonatal treatment with a PR antagonist impaired adult performance on a passive inhibitory avoidance task and an attentional setshifting task, measures of behavioral inhibition/impulsivity and cognitive flexibility, respectively. TH-ir levels in the VTA were reduced and cognitive flexibility was impaired in PR knockout mice as well. Conclusions: These findings provide novel insights into a potential role for PR in the developmental etiology of behavioral disorders that involve impairments in complex cognitive behaviors and have implications for the use of synthetic progestins in humans during critical neurodevelopmental periods.

๑) 2015 S. Karger AG, Basel

\section{Introduction}

The mesocortical dopamine pathway consists of dopaminergic projections from the midbrain ventral tegmental area (VTA; A10) to cortical areas, especially the prefrontal cortex (PFC). Dopamine release in the PFC is crit-

\section{KARGER}

E-Mail karger@karger.com

www.karger.com/nen
(C) 2015 S. Karger AG, Basel

0028-3835/15/1034-0207\$39.50/0
Jari Willing

Behavioral Neuroscience Division, Department of Psychology

University of Illinois at Urbana-Champaign

603 E Daniels St, Champaign, IL 61820 (USA)

E-Mail jwillin@illinois.edu 
ical for 'executive functions' such as attention, working memory, behavioral inhibition and cognitive flexibility. Even slight perturbations during critical periods of development can cause permanent alterations in the function of this pathway and may underlie some of the cognitive deficits in behavioral disorders such as schizophrenia [1, 2] and attention deficit disorder [3-7].

The mesocortical dopamine pathway may be sensitive to steroid hormone action during development. Nuclear steroid hormone receptors are powerful transcription factors and regulate fundamental processes of neural development. Progesterone receptor (PR) is expressed throughout the perinatal rat brain including brain regions associated with cognitive function [8-10]. PR immunoreactivity (PR-ir) and PR mRNA are transiently expressed in the subplate and pyramidal cell layers of all functional regions (frontal, motor, somatosensory, auditory and visual) of the fetal and neonatal cortex, including the PFC $[10,11]$. Preliminary data also suggest that PR is transiently expressed in the neonatal medial PFC (mPFC). In addition, $\mathrm{PR}$ is expressed during perinatal life in several midbrain nuclei including the VTA $[8,12]$. The timing of PR expression in the VTA and PFC corresponds to periods of significant dendritic maturation of $\mathrm{MPFC}$ neurons and synaptogenesis for dopaminergic axons within the frontal cortex [13-15], suggesting that PR activity may be important for establishing functional connectivity. Consistent with this idea, progesterone treatment during postnatal life increased the number of midbrain neurons expressing tyrosine hydroxylase $(\mathrm{TH})$, the ratelimiting enzyme in the synthesis of dopamine [16], and altered levels of dopamine and its metabolites in the PFC in adulthood [17].

The present study characterizes the full ontogeny and phenotype of PR-ir cells in the mesocortical pathway and tests the hypothesis that PR activity during perinatal life plays a critical role in the development of dopaminergic innervation of the MPFC and in subsequent mPFC-dependent cognitive behaviors in adulthood. Results demonstrate that $\mathrm{PR}$ is expressed in dopaminergic cells of the VTA and within VTA cells that project to the mPFC in neonates, and that inhibition of PR activity decreases dopaminergic innervation of the prelimbic (PL) $\mathrm{mPFC}$, decreases TH expression in the VTA and impairs cognitive flexibility and behavioral inhibition in adulthood. These results provide valuable insight into the normal development and potential susceptibilities of this critical behavioral circuit and further elucidate the importance of steroid hormones and their receptors in neural development.

\section{Methods}

Animals

All animal procedures were approved by the Institutional Animal Care and Use Committee at the University at Albany, SUNY. Pregnant female Sprague-Dawley rats were purchased from Taconic Laboratories (Germantown, N.Y., USA) at gestational day 16 and were allowed to deliver pups normally. The day of birth was designated as postnatal day 1 (P1). The mice used in this study were of a mixed background $(\mathrm{C} 129 \mathrm{SvEv} \times \mathrm{C} 57 \mathrm{Bl})$ and either homozygous for an insertional mutation in the PR gene (PRKO) or homozygous for the wild-type PR gene (WT). They were bred at the University of Albany, SUNY, by crossing heterozygous males and females. PRKO mice were created by the insertion of a neomycin resistance gene and a lacZ reporter gene into exon 1 , thereby inhibiting the synthesis of functional $P R$ transcripts and preventing the expression of both $P R_{A}$ and $\mathrm{PR}_{\mathrm{B}}$ isoforms of the receptor protein [18]. All animals were housed on a reverse 12-hour light/12-hour dark cycle at a constant temperature of $25 \pm 2{ }^{\circ} \mathrm{C}$ with food and water available ad libitum.

\section{RU 486 Administration}

Male rat pups were treated daily with the PR antagonist RU 486 (20 mg/kg, s.c., in sesame oil [19, 20]; Mifepristone; Sigma-Aldrich, St. Louis, Mo., USA) or an equal volume of the oil vehicle alone from $\mathrm{P} 1$ to $\mathrm{P} 14$, the period spanning peak PR expression in the VTA and PFC.

\section{Genotype Determination}

From mice, ear tissue was collected by ear punch for genotype determination. Tissue was first lysed using proteinase $\mathrm{K}$ in a water bath heated to $55^{\circ} \mathrm{C}$ overnight, after which total genomic DNA was purified and amplified using the Qiagen DNeasy Blood and Tissue kit. PCR was performed on purified DNA using three separate primers for PR and neomycin (PR: 5'-TAGACAGTGTCTTAGACTCGTTGTTG-3'; 5'-GATGGGCACATGGATGAAAC-3'; neomycin: $5^{\prime}$-GCATGCTCCAGACTGCCTTGGGAAA-3'). Using gel electrophoresis, the genotype was determined by the molecular weight of the extracted PCR product. Treatment groups were counterbalanced by litter, such that WT and PRKO mice from at least 5 different litters were represented in each group to avoid possible litter effects.

\section{Tissue Collection}

All rats and mice in these experiments were sexed using anogenital distance as a marker. Neonatal rats were anesthetized by hypothermia, while juvenile and adult rats and mice were administered a lethal injection of sodium pentobarbital (Sleepaway; Zoetis, Florham Park, N.J., USA). All animals were euthanized by decapitation, and the brains were rapidly removed and immersed in $5 \%$ acrolein in $0.1 \mathrm{M}$ phosphate buffer $(\mathrm{pH} \mathrm{7.6)}$ for $6 \mathrm{~h}$, then cryoprotected in $30 \%$ sucrose in $0.1 \mathrm{M}$ phosphate buffer for $72 \mathrm{~h}$. The brains were sectioned in the coronal plane at $50 \mu \mathrm{m}$ on a freezing microtome and stored in cryoprotectant (30\% sucrose, $0.1 \%$ polyvinylpyrrolidone-40 in ethylene glycol and $0.1 \mathrm{M}$ phosphate buffer) until immunocytochemical processing.

\section{PR Immunocytochemistry}

Free-floating sections were rinsed in $0.05 \mathrm{M}$ Tris-buffered saline (TBS), incubated in $1 \%$ sodium borohydride in TBS for 10 min, and blocked in TBS containing 20\% normal goat serum, $1 \%$ 
hydrogen peroxide and $1 \%$ bovine serum albumin for $30 \mathrm{~min}$. The sections were then incubated in primary antisera against PR (rabbit polyclonal; DAKO, Carpinteria, Calif., USA; 1:1,000 in TTG, i.e. TBS containing $0.3 \%$ Triton $\mathrm{X}-100$ and $2 \%$ normal goat serum) for $72 \mathrm{~h}$. These rabbit polyclonal antisera were raised against the following sequence of the PR protein: amino acids 533-547, which is the DNA-binding domain of the human PR protein and is contained in both A and B isoforms of the receptor [21]. The specificity of this antiserum has previously been demonstrated by our laboratory $[8,10]$. Nuclear immunoreactivity is completely eliminated by preabsorption of the $\mathrm{PR}$ antiserum overnight with either the antigen peptide or a 10-fold molar excess of human $\mathrm{PR}_{\mathrm{A}}$ and $\mathrm{PR}_{\mathrm{B}}$ proteins $[20,22]$ or when the primary antiserum was omitted. In addition, all immunoreactivity is absent in PRKO mice [10].

Following primary antibody incubation, sections were rinsed 3 times in TTG (5 min each) and placed in a solution containing $5 \mu \mathrm{g} / \mathrm{ml}$ goat anti-rabbit biotinylated secondary antibody in TTG for $90 \mathrm{~min}$ at room temperature, followed by incubation in AvidinBiotin Complex in TBS (Vectastain Elite Kit; Vector Laboratories Inc., Burlingame, Calif., USA) for $1 \mathrm{~h}$. The sections were then rinsed 3 times in TBS, then incubated in TBS containing $0.05 \%$ diaminobenzidine, $0.75 \mathrm{nM}$ nickel ammonium sulfate, $0.15 \% \beta$-Dglucose, $0.04 \%$ ammonium chloride and $0.001 \%$ glucose oxidase for $10 \mathrm{~min}$. After being rinsed in TBS, the sections were mounted on gelatin-coated slides and coverslipped with Permount (Fisher Scientific, Pittsburgh, Pa., USA).

\section{TH Immunocytochemistry}

The immunocytochemical procedures were the same as described above, except that tissue was incubated in $\mathrm{TH}$ antisera (rabbit polyclonal; Millipore, Billerica, Mass., USA) for $48 \mathrm{~h}$ at 1:50,000 for TH-ir cell bodies in the VTA, and at 1:1,000 for TH-ir fibers in the mPFC.

\section{Double Immunocytochemistry}

For the colocalization of PR-ir and TH-ir and the colocalization of PR-ir and FluoroGold (FG), free-floating sections were incubated in $1 \%$ sodium borohydride in TBS for $10 \mathrm{~min}$, then blocked in $20 \%$ normal goat serum, $1 \%$ bovine serum albumin and $1 \%$ hydrogen peroxide in TBS for $30 \mathrm{~min}$. The sections were incubated in both antisera against PR (1:500, rabbit polyclonal; DAKO) and antisera against TH (1:50,000, mouse monoclonal; Millipore) or antisera against PR (1:500) and antisera against FG (1:500, guinea pig monoclonal; Protos Biotech, New York, N.Y., USA) diluted in TTG for $72 \mathrm{~h}$. For adequate visualization of PR, the immunohistochemical signal was enhanced using the Tyramide Signal Amplification method (PerkinElmer Inc., Waltham, Mass., USA). Briefly, after primary antibody incubation, the tissue was incubated in biotinylated goat-anti-rabbit secondary antibody $(5 \mu \mathrm{g} / \mathrm{ml})$ in TTG for $90 \mathrm{~min}$ at room temperature, followed by streptavidin-horseradish peroxidase and biotinyl tyramide solutions. Finally, tissue was incubated for $1 \mathrm{~h}$ in a solution containing streptavidin-conjugated fluorophore to detect PR (1:200, Alexa Fluor 488; Invitrogen, Carlsbad, Calif., USA), along with a goat-anti-mouse, fluorescently tagged secondary antibody for the detection of TH, or goat-anti-guinea pig for FG (1:200, Alexa Fluor 568), both diluted in TBS. The sections were then mounted on slides and coverslipped with ProLong Gold Antifade reagent (Invitrogen).

PR and Mesocortical Development

\section{Behavioral Testing}

Male rats were raised/treated as described above. At P90, all experimental animals underwent daily pretest handling (1 min/ day) for 1 week prior to testing. One cohort of rats was tested on the inhibitory avoidance task. To test the effects of RU 486 on cognitive flexibility, an additional cohort of rats was tested on the attentional set-shifting task. Last, a cohort of adult WT and PRKO mice was used to test cognitive flexibility in the adapted water maze task [23]. For these mice, testing commenced at P60. All testing procedures were conducted by an experimenter blinded to treatment group.

\section{Experiment 1: Ontogeny of PR Expression in the Rat VTA} and $\mathrm{mPFC}$

For VTA ontogeny, caesarean sections were performed to collect fetal tissue on embryonic day 16 (E16), E18 and E20 (3 litters per age group). Briefly, pregnant females were given a lethal dose of sodium pentobarbital. The abdominal cavity was opened, and the uterine horns were removed and placed on ice. Following removal from the uterine horn, each fetus was placed on ice prior to sacrifice by decapitation. Neonatal brains were collected at P1, P7, P14 and P28 and fixed in 5\% acrolein. All tissue was fixed, cut and processed for immunocytochemistry for PR as described above. For mPFC ontogeny, animals were sacrificed at P2, P6, P10, P15, P20, P25 and P30. For both VTA and mPFC ontogeny, tissue from 5 males and 5 females was collected for each age group. For both VTA and mPFC ontogeny, the exact dates were chosen based on previous studies from our laboratory $[9,11]$.

A representative, anatomically matched section from the VTA and $\mathrm{mPFC}$ of each animal was selected for image analysis. Microscopic images were captured with a Nikon Eclipse E600 microscope fitted with a SPOT Insight camera connected to a Dell Inspiron computer. Scion Image software (Scion Corp., Frederick, Md., USA) was used to analyze the captured images. The relative amount of PR-ir was determined as described previously [20, 24] by measuring the area (in $\mu \mathrm{m}^{2}$ ) covered by 'thresholded' pixels [i.e. those pixels with a gray level higher than a defined threshold density (specific immunoreactive staining)]. The threshold was determined as a constant function of the background optical density defined as the mean optical density 3-5 SDs higher than the mean background density. The mean background density was measured in a region devoid of PR-ir immediately adjacent to the analyzed region containing $\mathrm{PR}$-ir. Statistical analyses were performed for each region using a two-way ANOVA (sex $\times$ age), followed by preplanned post hoc comparisons using the Student-Newman-Keuls test $(\mathrm{p}<0.05)$.

Experiment 2: Characterization of the Phenotype of PR-ir Cells in the Neonatal Rat VTA

Experiment 2a: PR Expression in Dopaminergic Cells of the VTA during Development. Tissue was collected from 5 male and $5 \mathrm{fe}-$ male rats at $\mathrm{P} 1$ and $\mathrm{P} 7$, and processed for double immunocytochemistry for PR-ir and TH-ir as described above. Analysis of the coexpression of PR and TH was conducted using a Zeiss LSM 510 confocal microscope. Images were taken sequentially at $\times 63$ magnification using an argon laser for 488-nm wavelengths (for PR detection) and a HeNe laser for 568-nm wavelengths (for TH detection). The $\mathrm{z}$-stack consisted of 21 sequential images at $1 \mu \mathrm{m}$ each. For each animal, 3 matching representative brain sections through the VTA were investigated. For each of the 3 sections per 
animal, 10 cells which were immunoreactive for PR were sampled at $\times 63$ magnification from 2 different sites per section, i.e. from the parabrachial and paranigral subregions of the VTA, such that approximately 30 cells from each animal were considered for this analysis. From this sample, the percentage of cells that was immunoreactive for both PR and TH was estimated.

Experiment 2b: PR Expression in VTA Cells Projecting to the $m P F C$. Male and female pups $(\mathrm{n}=20)$ were anesthetized by hypothermia on $\mathrm{P} 3$, and their heads were secured using a stereotaxic apparatus adapted for neonatal rats (David Kopf Instruments, Tujunga, Calif., USA). Using neonatal rat stereotaxic coordinates (1.5-2.5 $\mathrm{mm}$ ventral, $2.0 \mathrm{~mm}$ rostral to the bregma) [25], a 1.0- $\mu$ l Hamilton syringe needle containing FG (hydroxystilbamidine: $0.2 \mu \mathrm{l}$ of $2 \%$ FG in sterile water) was lowered through the skull and into the frontal cortex targeting the PL and infralimbic (IL) mPFC. FG was injected using a microinfusion pump (World Precision Instruments, Sarasota, Fla., USA) at $0.005 \mu \mathrm{l} / \mathrm{s}$. Following recovery from anesthesia, the pups were returned to their home cages for a 3-day survival period, after which brain tissue was collected at P6, as described above, and immersion fixed in 5\% acrolein. FG fluorescence was analyzed on sections through the mPFC to determine the accuracy and the extent of the FG injections. Only animals whose FG injections were limited to the PL and IL MPFC were included for this analysis. While all injections hit the mPFC, a total of 7 animals were excluded from the study due to the fact that the FG infiltration tissue was outside of the PL/IL region. In addition, as a control for FG specificity, 2 animals intentionally received injections into the striatum. In these animals, it was confirmed that FG-labeled cells were observable in the substantia nigra and not in the VTA. Analysis of PR and FG colocalization was conducted on the remaining 11 animals (6 male, 5 female). Sections through the VTA were immunocytochemically processed for FG and PR-ir as described above. Three representative matching sections from the VTA were chosen for each animal. Confocal images at $\times 63$ magnification were taken sequentially using an argon laser for 488-nm wavelengths (for PR detection) and a HeNe laser for 568-nm wavelengths (for FG detection). Analysis was limited to regions of the VTA that contained both PR and FG staining. From the 3 sections used, approximately 10 PR-ir cells per section were randomly selected for a total of 30 cells per animal. A semiquantitative assessment of the percentage of PR-ir cells in the VTA that were colocalized with FG was conducted.

Experiment 3: PR Activity during Development and Levels of TH in the VTA

Because no sex differences were observed in the expression of PR or in the phenotype of PR-ir cells, the following studies were conducted on male rats treated with sesame oil or RU 486 as well as on male WT and PRKO mice. Brain tissue was collected from male rats (RU 486 and oil treated) at P25 and P90 and from male mice (WT and PRKO) at P25 and P70 ( $\mathrm{n}=9$ or 10 per group). P25 represents the developmental period prior to significant synaptic pruning in the $\mathrm{mPFC}$, and P70 (in mice) and P90 (in rats) represents the adult stage of full maturity of the mPFC [26-29]. Tissue was processed for TH immunocytochemistry as described above. The density of TH-expressing cells was determined in 1 matching representative section from each animal. Labeled TH-ir cells were counted in 1 representative section containing the parabrachial and paranigral VTA using a $10 \times 10$ grid reticule attached to the eyepiece of a Nikon Eclipse E600 microscope. This grid was large enough that all $\mathrm{TH}$-ir cells within the representative section were counted.
Additionally, using Scion Image software, TH optical density was measured in the VTA to determine relative levels of TH expression as opposed to the number of cells expressing TH. Using Scion Image software, the VTA from 1 representative, anatomically matched section per animal was digitally traced, defined by borders outlined in Paxinos and Watson [30]. Using a $\times 20$ objective, photographs were acquired as described in experiment 1 . The optical density scale used to measure relative $\mathrm{TH}$ immunoreactivity was inverted so that 0 was white and 254 was black (i.e., a higher number indicating higher relative levels of $\mathrm{TH}$-ir). $\mathrm{t}$ tests were used for the experiments using rats and mice for TH cell counts and TH optical density.

\section{Experiment 4: PR Activity during Development and}

Dopaminergic Innervation of the $\mathrm{mPFC}$

Sections containing PFC were collected/processed from animals used in experiment 3 and processed for TH immunocytochemistry as described above. Analysis of TH fiber density in the mPFC was accomplished using previously established methods [31]. Briefly, representative, anatomically matched sections through the $\mathrm{mPFC}$ were used to capture photographs in darkfield illumination using a Model 1.3.0 SPOT digital camera (Diagnostic Instruments Inc., Sterling Heights, Mich., USA) attached to a Nikon E600 microscope using a $\times 20$ objective. The density of TH-ir fibers (area covered by thresholded pixels per square unit area) was quantified using Scion Image software as described previously. Thresholded pixels were distinguished as being above a predetermined background level that was devoid of TH staining. Separate photographs were acquired from layers I-II and from layers V-VI. A separation of these layers is identifiable based on TH-ir fiber orientation [32, 33]. The PL mPFC was identified based on proximity to the forceps minor of the corpus callosum, easily identifiable by its white matter composition [30]. Treatment groups were compared using separate Student $\mathrm{t}$ tests for layers II and V of each mPFC subregion.

Experiment 5: PR Activity during Neonatal Life in Rats and Behavioral Inhibition in Adulthood

Neonatal rats were treated as described above with either RU 486 or sesame oil ( $n=9$ per group). In adulthood, the animals underwent a 2 -trial passive inhibitory avoidance task. This task measures both long-term memory of negative consequences and behavioral inhibition and may be influenced by activity in the mPFC [34-36]. In trial 1, rats were placed into a chamber lit by ambient room light, with access to an adjoining, enclosed, dark chamber, which was accessible via the opening of an electronic door after a 30 -second habituation period. One second after the rats entered the dark chamber, they received a mild, but aversive, inescapable foot shock $(0.5 \mathrm{~mA}, 3 \mathrm{~s})$. In trial 2, $48 \mathrm{~h}$ later, the rats were placed back into the lit chamber, and the latency to reenter the dark chamber was measured, with a maximum latency of $900 \mathrm{~s}$. A shorter latency to reenter the dark chamber is indicative of impaired memory and/or a deficit in behavioral inhibition. A two-way ANOVA (day $\times$ treatment) was used to assess performance across days, followed by a nonparametric Mann-Whitney U test to compare latencies on the second day of the task.

Experiment 6: Inhibition of PR Activity during Neonatal Life and Cognitive Flexibility in Adulthood

Attentional Set-Shifting Task in Rats. Neonatal rats were treated as described above with RU 486 or sesame oil ( $n=9$ per group) 
and tested at P90 on the attentional set-shifting task, which assesses cognitive flexibility in rats. Prior to testing, food was restricted to $15 \mathrm{~g}$ /day, maintaining the body weight at $80-90 \%$ of the freefeeding weight to ensure motivation for a food reward. The animals were handled and weighed daily to ensure that their body weights did not drop below $80 \%$ of the free-feeding weight. The testing apparatus is an adaptation of a plus maze, in which the arms of the maze are painted either white or black and the floors have either a rough or a smooth texture. All experimental procedures are identical to those described in Stefani and Moghaddam [37].

Pretesting Procedures. All animals underwent extensive pretest handling and habituation to the apparatus for 11 days prior to testing. Food restriction was continued throughout the testing procedure. On days 1-5, each animal was handled by the experimenter for $1 \mathrm{~min}$, then given 3-4 sucrose pellets ( $45 \mathrm{mg}$, Dustless Precision Pellets; Bio-Serv, Frenchtown, N.J., USA) in their home cages. On days $6-8$, the rats underwent maze habituation in which all 4 arms of the maze were baited with sucrose pellets. The habituation trials lasted until all pellets were eaten or a maximum of $5 \mathrm{~min}$. On days 9-11, 1 arm of the maze was blocked, and the animals were trained to make an 'arm choice' by leaving the start arm and entering 1 of 2 open arms of the maze. For these days, there were 8 consecutive training trials in which $50 \%$ of their choices were rewarded in a random manner.

Testing Procedures. Testing was conducted on 2 consecutive days, consisting of multiple trials on each day ('sets' 1 and 2). For both sets, the maze was arranged as it was in the training trials such that animals placed in alternating start arms always had an option of turning right or left into 1 of 2 target arms. In set 1 , the animals were trained to enter baited arms using 1 specific cue (based on arm color or texture) to earn a food reward. Set 1 ended when a performance criterion of 8 consecutive correct trials was met. Animals unable to reach this criterion within 120 trials were excluded from the study. In set 2 ( $24 \mathrm{~h}$ later), the 'rule' or contingency for the reward was changed to a different sensory modality (e.g. food reward switched from light arms to rough arms). In set 2, all animals completed 80 trials regardless of performance. This extradimensional shift (from one sensory domain to another) is dependent on dopaminergic activity in the mPFC [38-42]. The number of trials to achieve the criterion on test day 1 , the percentage of trials with correct choices across trial 'blocks' ( 8 consecutive trials per block) on test day 2 and the number of perseverative errors (i.e. incorrect responses based on the reward contingency from test day 1) were analyzed. A perseveration error was defined as making a choice indicative of the first rule association after the rule has changed in set 2. 'Omission' errors, incorrect choices that are not representative of either rule 1 or rule 2, were also counted. Because of the cap on the maximum number of trials, trials to criterion in set 1 were analyzed using the Mann-Whitney U test. A two-way ANOVA (treatment $\times$ trial block) was used to analyze the percentage of correct choices across set 2 . Additionally, separate two-way ANOVAs were conducted for the first half (trial blocks 1-5) and the second half (trial blocks 1-6). Student's t tests were used to compare the number of perseveration and omission errors between groups on set 2 .

Water Maze Task in Adult WT and PRKO Mice. WT and PRKO mice ( $\mathrm{n}=10$ per group) were tested on a water maze task at P60. Procedures for this adapted water maze test were adopted from Karatsoreos et al. [23] to assess cognitive flexibility in mice. Male WT and PRKO mice were housed with littermates throughout the duration of testing, and all tests were conducted during the animals' dark phase to enhance the activity level. Testing was conducted in a plastic tank filled with water $\left(26^{\circ} \mathrm{C}\right)$ made opaque with powdered milk. Trials were recorded using ANY-maze behaviortracking software (Stoelting, Wood Dale, Ill., USA) by an experimenter blinded to treatment group. The task occurred over 5 consecutive days ( 4 trials per day). In each trial, the latency to reach a 'safety' platform was recorded, with a maximum latency of $60 \mathrm{~s}$. On day 1, to assess swimming ability and motivation, animals were placed into the maze with a visible platform. On days 2 and 3, the platform remained in the same location in the maze but was submerged below the water surface and was no longer visible, requiring spatial memory of the location of the platform. Latency to reach the platform on days 2 and 3 assesses long-term spatial memory. On day 4 , the location of the platform was moved to an opposite quadrant of the maze, requiring the animals to learn this new location. On day 5 , the platform was in the same location as on day 4. Latency to reach the platform on days 4 and 5 represents cognitive flexibility, the ability to learn the position of the new platform location while inhibiting the tendency to revert back to the first location of the safety platform. On days 4 and 5, the number of entries into the 'old quadrant' (the quadrant where the platform was located on days 1-3) was recorded as perseveration errors [23]. Swim speed was also recorded for all trials as a control to ensure that differences in latency were indicative of differences in cognition and not of motor abnormalities. Differences in the latency to reach the platform across days were analyzed using two-way repeated-measures ANOVA (genotype $\times$ day). Student's t tests were used for between-group comparisons of swim speed (in $\mathrm{cm} / \mathrm{s}$ ) and entries into the old quadrant.

\section{Results}

\section{Experiment 1: PR Is Transiently Expressed in the Rat $V T A$ and $m P F C$ during Neonatal Life}

Preliminary evidence suggested that PR was expressed in both the VTA and the mPFC during development in the rat. In the first experiment, we sought to determine the developmental window during which PR-ir cells are present in the VTA and $\mathrm{mPFC}$.

\section{Ventral Tegmental Area}

PR-ir was not observed at E16, E18 or E21. However, PR-ir was present within the parabrachial and paranigral VTA on P1, P7 and P14 but absent by P28 (fig. 1a). For the relative amount of PR-ir in the VTA, a two-way ANOVA (age $\times$ sex) revealed a significant main effect of age $\left(F_{2,29}=21.988, p<0.001\right)$ but no significant effect of sex $(\mathrm{p}=0.923)$ and no significant interaction $(\mathrm{p}=0.780)$. PR expression in the VTA was highest on P1 in males and females, and thereafter declined by P7 and P14 ( $<<0.05)$ and was virtually absent by P28. Student-Newman-Keuls post hoc analysis revealed a significant difference between P1 and both P7 and P14 ( $<<0.05)$. 

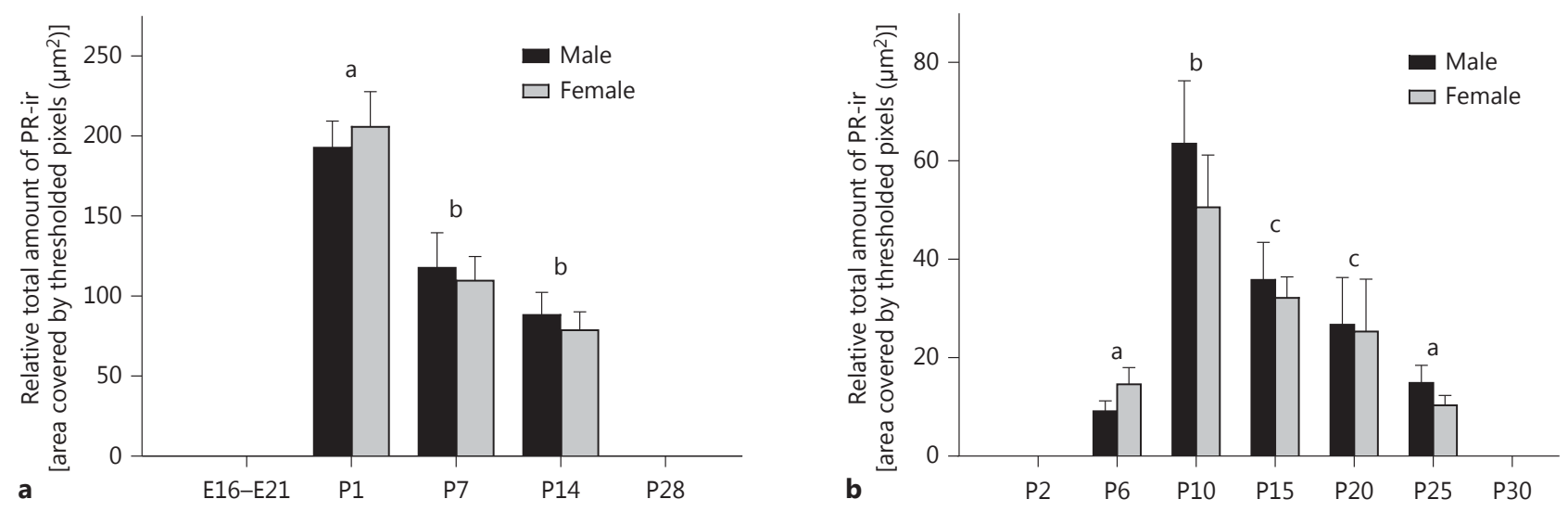

Fig. 1. Transient expression of PR in the rat VTA and mPFC during development. The mean $( \pm$ SEM) relevant total amount of nuclear PR-ir in the VTA (a) and the PL $\operatorname{mPFC}(\mathbf{b})$ is shown. a Nuclear PR-ir was not detectable in the VTA prenatally (E16E21), was transiently expressed from the day of birth (P1) through at least P14 and was absent by P28. PR-ir levels were highest on

\section{Medial Prefrontal Cortex}

PR-ir was present in layers II and III of the mPFC. PR expression was first detected on P6, peaked on P10, then progressively declined, and was undetectable at P30 (fig. 1b). A two-way ANOVA (age $\times$ sex) revealed a main effect of age $\left(\mathrm{F}_{4,50}=11.623, \mathrm{p}<0.001\right)$, no effect of sex $(\mathrm{p}=0.512)$ and no age-by-sex interaction $(\mathrm{p}=0.837)$. The post hoc analysis revealed a significant difference between P10 and every other age examined. No PR-ir cells were detected in any other mPFC layer. PR-ir was not detected at P2 or P30.

Experiment 2: PR Is Expressed in Dopaminergic Cells and Cells Projecting to the mPFC in the Rat VTA

In order to determine if $\mathrm{PR}$ was expressed in dopaminergic cells of the VTA, we examined the colocalization of PR-ir and TH-ir in males and females on P1 and P7 using confocal microscopy. In both sexes, $>90 \%$ of PR-ir cells also contained TH-ir at P1 and P7 in the parabrachial and paranigral subdivisions of the VTA (fig. 2). THir was limited to the cytoplasm and dendrites, allowing for clear visualization of PR-ir in the nucleus of individual cells.

Because PR was expressed in dopaminergic projection neurons of the VTA, we next examined whether PR was expressed in VTA cells that project to the $\mathrm{MPFC}$. The ret-
P1, with a significant decline at P7 and P14. b In the mPFC, PR-ir was not detectable on P2, was expressed from P6 through P25 (peaking around P10) and was absent by P30. Postnatal ages with differing letters were significantly different from one another $(\mathrm{p}<$ $0.05)$. There was no significant effect of sex at any age in either region.

rograde tracer FG was injected into the PL and IL mPFC on P3, and confocal microscopy was used to examine the colocalization of FG and PR-ir in VTA on P6. FG injections that were limited to the PL/IL mPFC (fig. 3a) labeled many cells of the VTA (fig. 3b). FG injections that missed the PL/IL mPFC resulted in no FG labeling of the VTA. As an additional specificity control, FG injections intentionally made into the striatum labeled cells in the substantia nigra but not in the VTA. Approximately $50 \%$ of the FG-labeled cells in the VTA also expressed nuclear PR-ir (fig. 3c, d). It is important to note that in addition to the PR/FG colocalized cells, approximately $50 \%$ of the PR-ir cells were not immunoreactive for FG as well, and approximately $50-60 \%$ of the FG-ir cells did not express $\mathrm{PR}$. Taken together, these results suggest that PR is transiently expressed during development in midbrain VTA cells of the mesocortical dopaminergic pathway to the mPFC.

\section{Experiment 3: PR Activity during Development \\ Regulates Levels of TH in the VTA}

$\mathrm{PR}$ is transiently expressed in dopaminergic cells of the VTA during postnatal development. To determine whether PR activity may regulate dopamine synthesis later in life, we examined mean levels of TH-ir per cell in the VTA in rats treated with a PR antagonist during neonatal 
Fig. 2. $P R$ is expressed in dopaminergic cells of the rat VTA. Colocalization of PR-ir (green; nuclear) and TH-ir (red; cytoplasmic) in the neonatal VTA is shown. a P1 male. b P1 female. c P7 male. d P7 female. More than $90 \%$ of the PR-ir cells in the parabrachial VTA were dopaminergic.

Fig. 3. PR is expressed in VTA cells that project to the mPFC in neonatal rats also immunoreactive for PR. The retrograde tracer FG was injected into the PL and IL mPFC and labeled cells of the VTA that were immunoreactive for PR. a FG-ir within the IL and PL MPFC at the injection site. b Retrogradely labeled FG-ir cells within the parabrachial VTA (PB-VTA). c, d Colocalization of PR-ir (green; nuclear) and FG-ir (red; cytoplasmic) in the VTA of a male rat at $\mathrm{P} 6$.

PR and Mesocortical Development
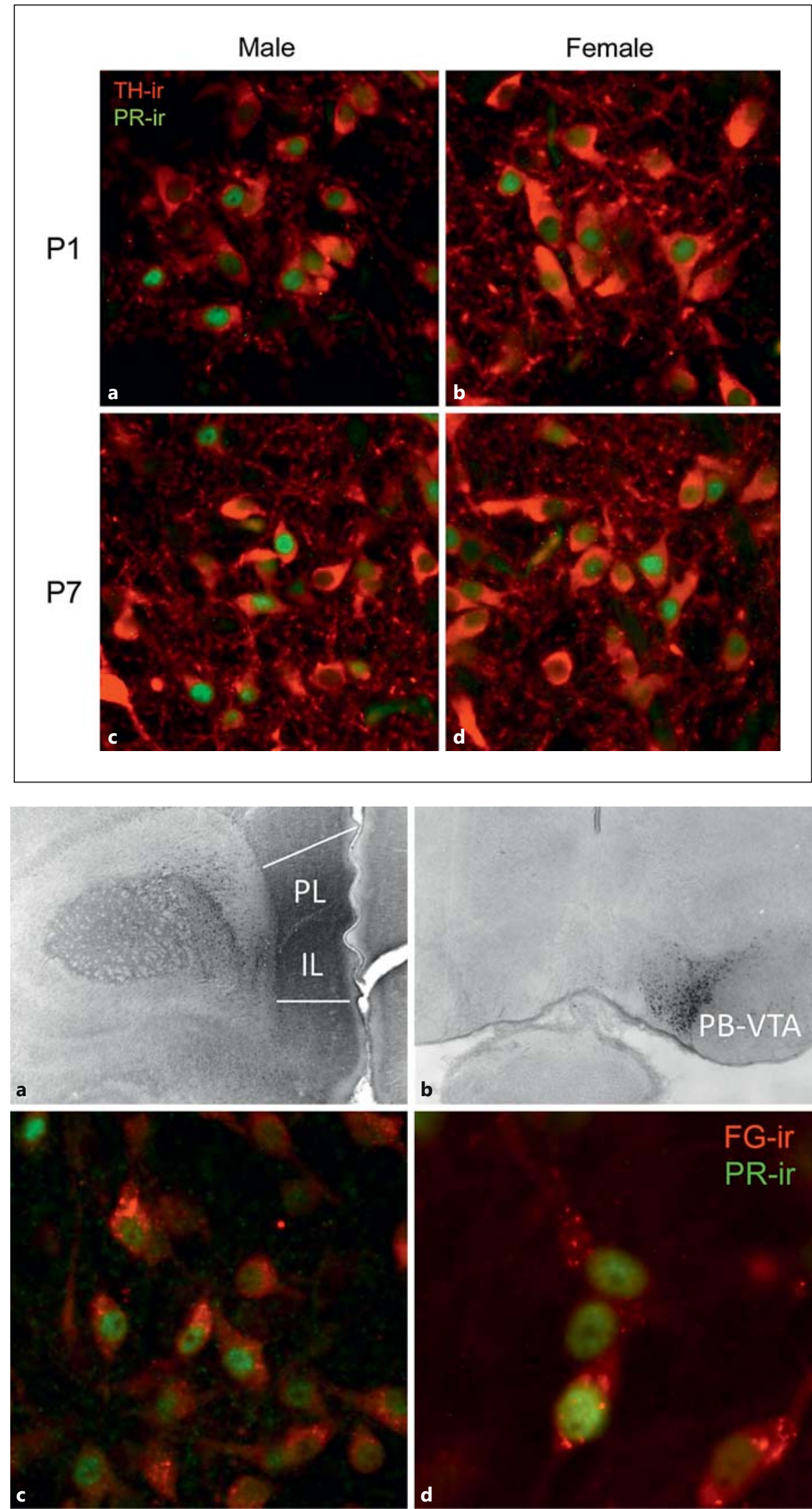
Fig. 4. Inhibition of $P R$ activity during development decreases TH levels in the adult VTA. Relative total amounts of TH-ir in the VTA of P25 (a) or P90 rats (b) following administration of the $\mathrm{PR}$ antagonist $\mathrm{RU}$ $486(20 \mathrm{mg} / \mathrm{kg})$ or the oil vehicle during neonatal life, or in the VTA of P25 (c) or P70 WT or PRKO mice (d) are shown. Data are presented as means \pm SEM. * Significantly different from same-age counterparts at $\mathrm{p}<0.05$.

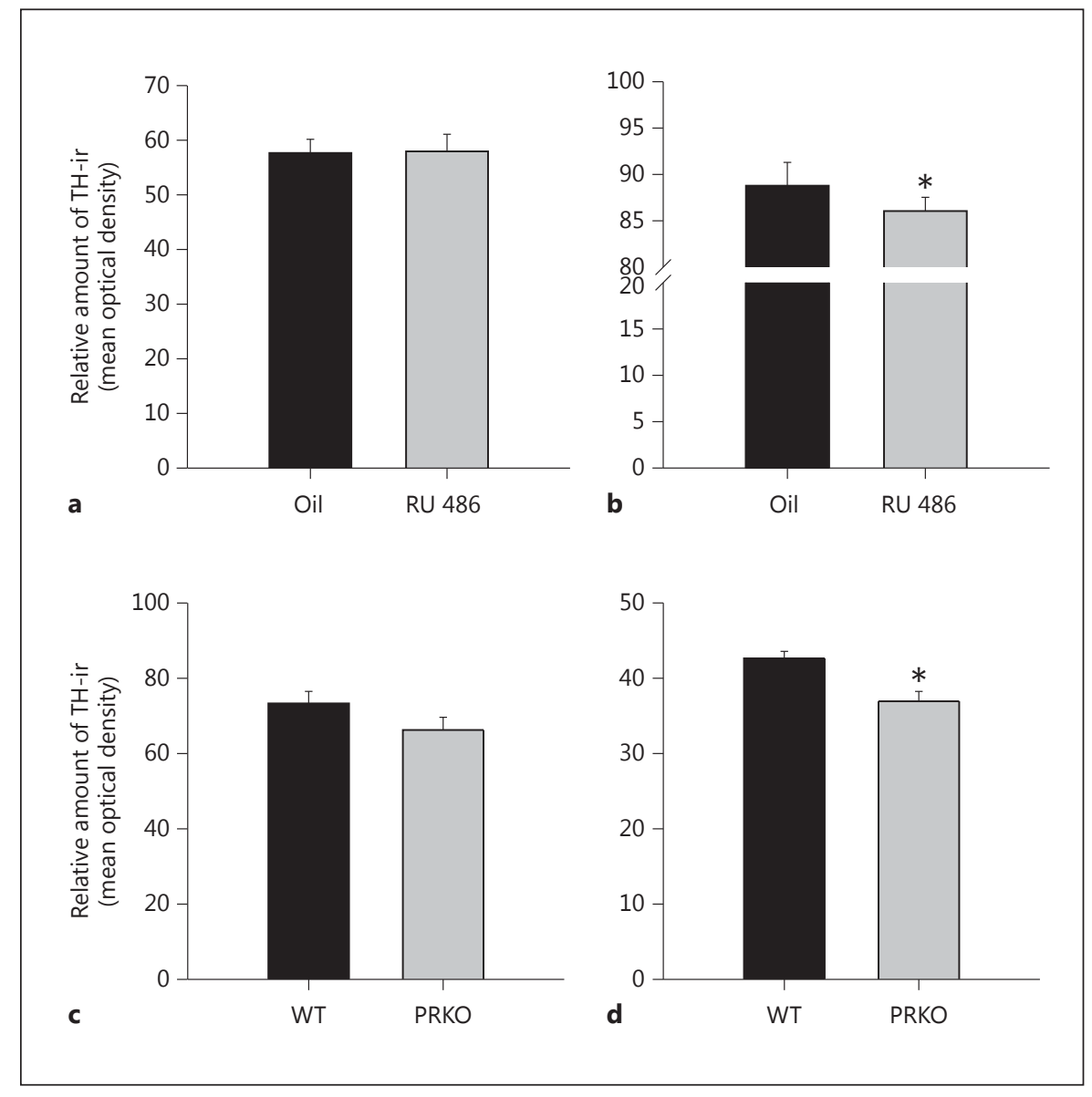

life as well as in both juvenile and adult PRKO mice. At P25, there was no effect of RU 486 treatment in rats, or genotype in mice, on relative levels of TH-ir in the VTA (optical density) (fig. 4a, c). In contrast, levels of TH-ir were significantly lower in the VTA of RU 486-treated rats $(\mathrm{t}=2.681, \mathrm{p}=0.017)$ and PRKO mice $(\mathrm{t}=2.587, \mathrm{p}=$ 0.012 ) compared to controls in adulthood (P90 and P70, respectively) (fig. $4 \mathrm{~b}, \mathrm{~d}$ ). There was no effect of treatment or genotype on the number of TH-ir cells in the VTA at P25 or in adulthood for either rats or mice (data not shown). These results suggest that disruption of PR activity during early life alters the development of the VTA in such a way as to decrease dopamine synthesis sometime after, but not prior to, adolescence.

\section{Experiment 4: PR Activity during Development}

Influences Dopaminergic Innervation of the $m P F C$

$\mathrm{PR}$ is transiently expressed in dopaminergic cells of the VTA during a period of dopaminergic synaptogenesis and pruning in the PFC. We therefore tested the hypoth- esis that PR activity during neonatal life is important for dopaminergic innervation of the mPFC. Neonatal administration of RU 486 to rats significantly decreased the density of TH-ir fibers within layer II of the PL mPFC in rats at $\mathrm{P} 25(\mathrm{t}=2.44, \mathrm{p}=0.024)$ but not at P90 (fig. 5a, b). RU 486 had no significant effect on TH-ir fiber density in layer $\mathrm{V}$ at either age in rats (data not shown). In mice, there were no effects of genotype on $\mathrm{TH}$-ir fiber density in either layer V or layer II of the P25 or P70 mouse mPFC (fig. 5c, d).

\section{Experiment 5: Inhibition of PR Activity during} Development Increases Impulsivity in Adulthood

The evidence thus far suggests that PR is transiently expressed in both the MPFC and in dopaminergic cells of the VTA that project to the MPFC, generating the hypothesis that $\mathrm{PR}$ activity during development may be important for cognitive behaviors in which the mesocortical dopamine pathway is critical. In the first behavioral experiment, we examined behavioral inhibition/impul- 
Fig. 5. Inhibition of PR activity during development alters dopaminergic innervation of the $\mathrm{mPFC}$ in adolescent rats. Relative density of TH-ir fibers within layer II of the PL mPFC in rats at P25 (a) or P90 (b) following administration of the PR antagonist or the oil vehicle during neonatal life. There was a trend toward reduced $\mathrm{TH}$-ir fiber density in the mPFC of PRKO mice at P25 (c); there were no significant differences in the mouse $\mathrm{mPFC}$ at either age $(\mathbf{c}, \mathbf{d})$. Data are presented as means \pm SEM. ${ }^{*} \mathrm{p}<$ 0.05 .
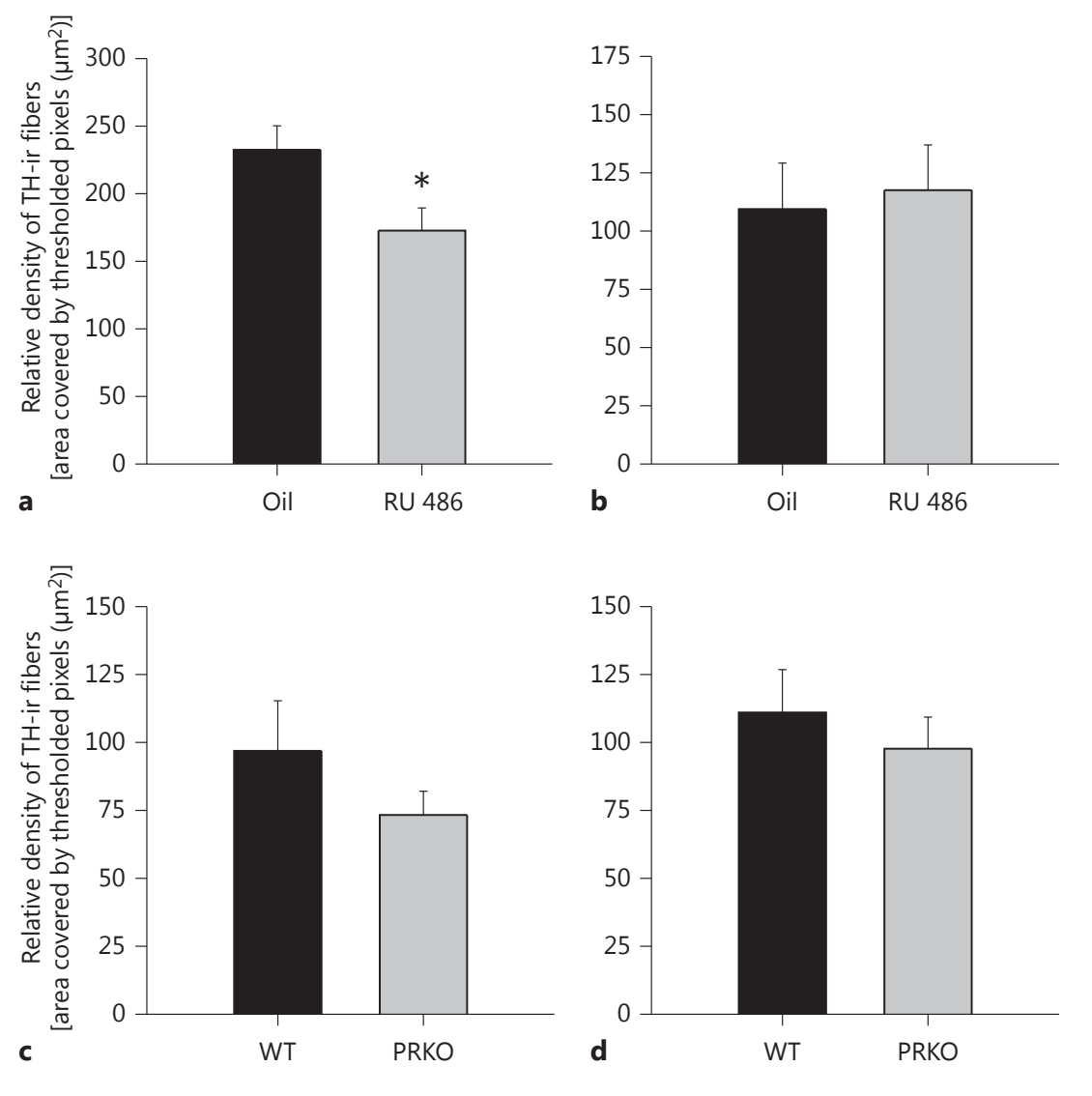

sivity using the active avoidance task in adult rats treated with the PR antagonist as neonates. A two-way ANOVA revealed a significant main effect of treatment $\left(\mathrm{F}_{1,17}=\right.$ $4.938, \mathrm{p}=0.035)$, a main effect of day $\left(\mathrm{F}_{1,17}=59.165\right.$, $\mathrm{p}=0.034)$ and a significant treatment-by-day interaction $\left(\mathrm{F}_{1,17}=4.942, \mathrm{p}=0.034\right)$ (fig. 6$)$. Two follow-up nonparametric Mann-Whitney rank-sum tests showed that there was no difference between groups on day 1 but there was a significant difference in latency on day 2 $(\mathrm{T}=38.0, \mathrm{p}=0.04)$. Control rats approached the maximum latency, whereas RU 486-treated rats entered the dark chamber after about half the time. These results suggest that disruption of PR activity during development impairs the long-term memory for an aversive event and/or behavioral inhibition, the ability to inhibit a motivated behavior despite a previous, negative consequence. This may also be interpreted as an increase in impulsivity (i.e. engaging in a behavior without considering potential risks.

PR and Mesocortical Development

\section{Experiment 6: Disruption of PR Activity during} Development Impairs Cognitive Flexibility and Increases Perseveration in Adult Rats and Mice

To examine the role of PR activity in cognitive flexibility, which is dependent upon dopamine release in the mPFC, we utilized the attentional set-shifting task in adult rats treated neonatally with the PR antagonist, or we used an adapted water maze in adult PRKO mice.

\section{Attentional Set-Shifting Task in Rats}

In the initial rule-learning association trials (set 1), neonatal RU 486 administration increased the number of trials required to reach the criterion of 8 consecutive correct choices compared to controls $(t=-2.462, \mathrm{p}=0.026)$ (fig. 7a), suggesting that RU 486-treated rats were slower to learn the initial rule. Additionally, 1 animal from the RU 486 group failed to reach the criterion within 120 trials and was excluded from the study. Nonetheless, all rats from both groups reached the criterion and therefore went into set 2 at similar levels of performance on the first 


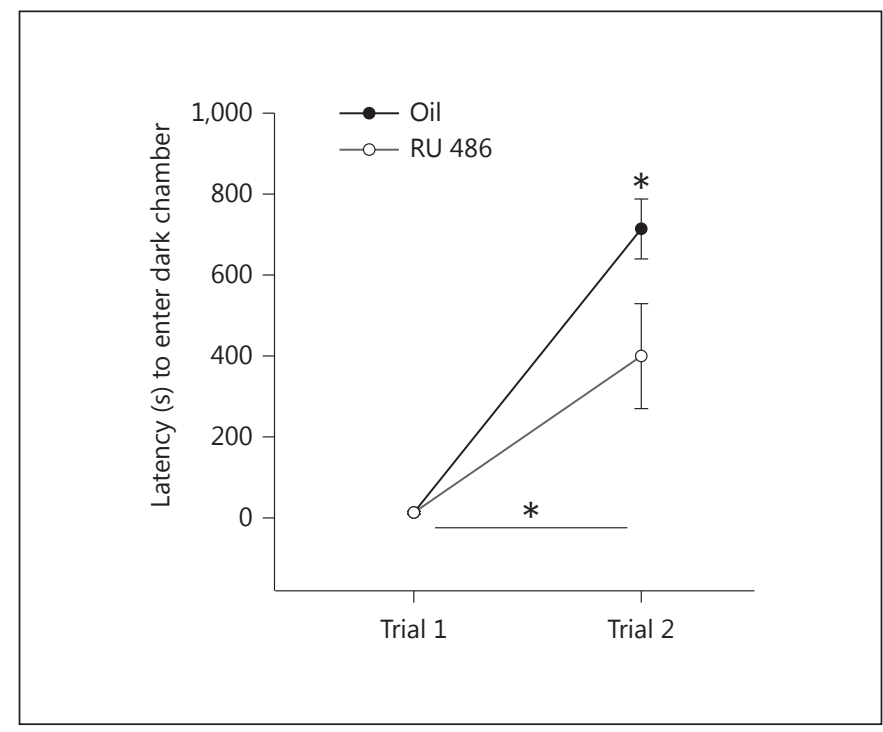

Fig. 6. Inhibition of PR activity during neonatal life decreases behavioral inhibition/increases impulsivity in adulthood. Neonatal administration of the PR antagonist RU 486 impaired performance on the inhibitory avoidance task compared to oil-treated controls. The latency to enter the dark chamber was not significantly different between the groups in trial 1. In trial 2, both groups had significantly longer latencies compared to trial 1, i.e., in effect, an avoidance of the dark chamber, indicating a memory for the aversive event in trial 1 in both groups. However, the latency to enter the dark chamber was significantly shorter for RU 486-treated rats in trial 2 compared to controls, suggesting an impaired ability to inhibit a motivated response or an increase in impulsivity. Data are presented as means \pm SEM. ${ }^{*} \mathrm{p}<0.05$.

rule. RU 486-treated animals again required significantly more trials to reach the 8 consecutive correct choices in set $2(t=-2.275, p=0.039)$ (fig. $7 b)$.

In set 2 , the rule was changed to a different sensory modality (e.g. from light to rough arms baited, an extradimensional shift). Both groups performed at about baseline levels for trial blocks 1-5. However, at about trial block 6 , control rats made the 'shift' to the new rule and achieved $>90 \%$ correct responses by trial block 10 . In contrast, RU 486-treated rats were slower to make the shift to the new rule and never performed quite as well as controls (fig. 7c). A two-way repeated-measures ANOVA of trial blocks 1-5 revealed no significant main effect of trial block, no significant effect of treatment and no significant interaction. However, in trial blocks 6-10, there was a significant main effect of trial block $\left(\mathrm{F}_{9,159}=11.760\right.$, $\mathrm{p}<$ 0.001 ) and treatment $\left(\mathrm{F}_{1,159}=4.756, \mathrm{p}=0.031\right)$ (fig. $7 \mathrm{c}$ ), with no significant interaction between trial block and treatment.
The number of perseveration errors (incorrect responses made using the old rule) did not differ between the groups in trial blocks 1-5 (both groups displayed a high number of perseveration errors). However, in trial blocks 6-10, RU 486-treated rats continued to make perseveration errors, and they made significantly more perseveration errors than controls $(t=-2.152, p=0.049)$ (fig. $7 f$, g). In contrast, the number of omission errors (incorrect responses using neither the old nor the new rule) did not differ between the groups in either trial blocks $1-5$ or 6-10 (fig. 7d, e). Taken together, these results suggest that disruption of PR activity during development impairs cognitive flexibility and increases perseverative behavior.

Water Maze Task in Adult WT and PRKO Mice

We next examined the role of PR in cognitive flexibility using PRKO mice in an adapted water maze. WT and PRKO mice did not differ in their ability to learn the placement of a hidden platform. However, when the location of the hidden platform was changed, PRKO mice were slower to shift to the new location, and they made significantly more perseveration errors. A two-way repeated-measures ANOVA revealed a significant interaction between genotype and test day $\left(\mathrm{F}_{4,100}=2.770, \mathrm{p}=\right.$ $0.034)$, a significant main effect of test day $\left(\mathrm{F}_{4,100}=28.439\right.$, $\mathrm{p}<0.001)$ and no significant main effect of genotype (fig. 8a). Post hoc tests revealed that PRKO mice had a significantly longer latency to reach the platform on test day 4 ( $\mathrm{p}<0.05)$, the first day the platform was moved to the new quadrant. There were no significant effects of genotype on any other test day. In addition, PRKO mice committed significantly more perseveration errors (i.e. entries into the previously correct quadrant) on test days $4(\mathrm{t}=2.271, \mathrm{p}=0.036)$ and $5(\mathrm{t}=2.221, \mathrm{p}=0.04)$ (fig. $8 \mathrm{c}$, d). There were no significant differences in swim speed between PRKO and WT mice across all test days (fig. 8b). The results for PRKO mice are consistent with the findings for rats and suggest that PR expression is important in cognitive flexibility. An absence of functional PR expression increases perseverative behavior.

\section{Discussion}

Fundamental processes of early neurodevelopment are critical for the proper maturation of mesocortical connectivity and for subsequent cognitive function [26, $27,43]$. The present results support the idea that the activity of PR, a powerful transcription factor, during neonatal 


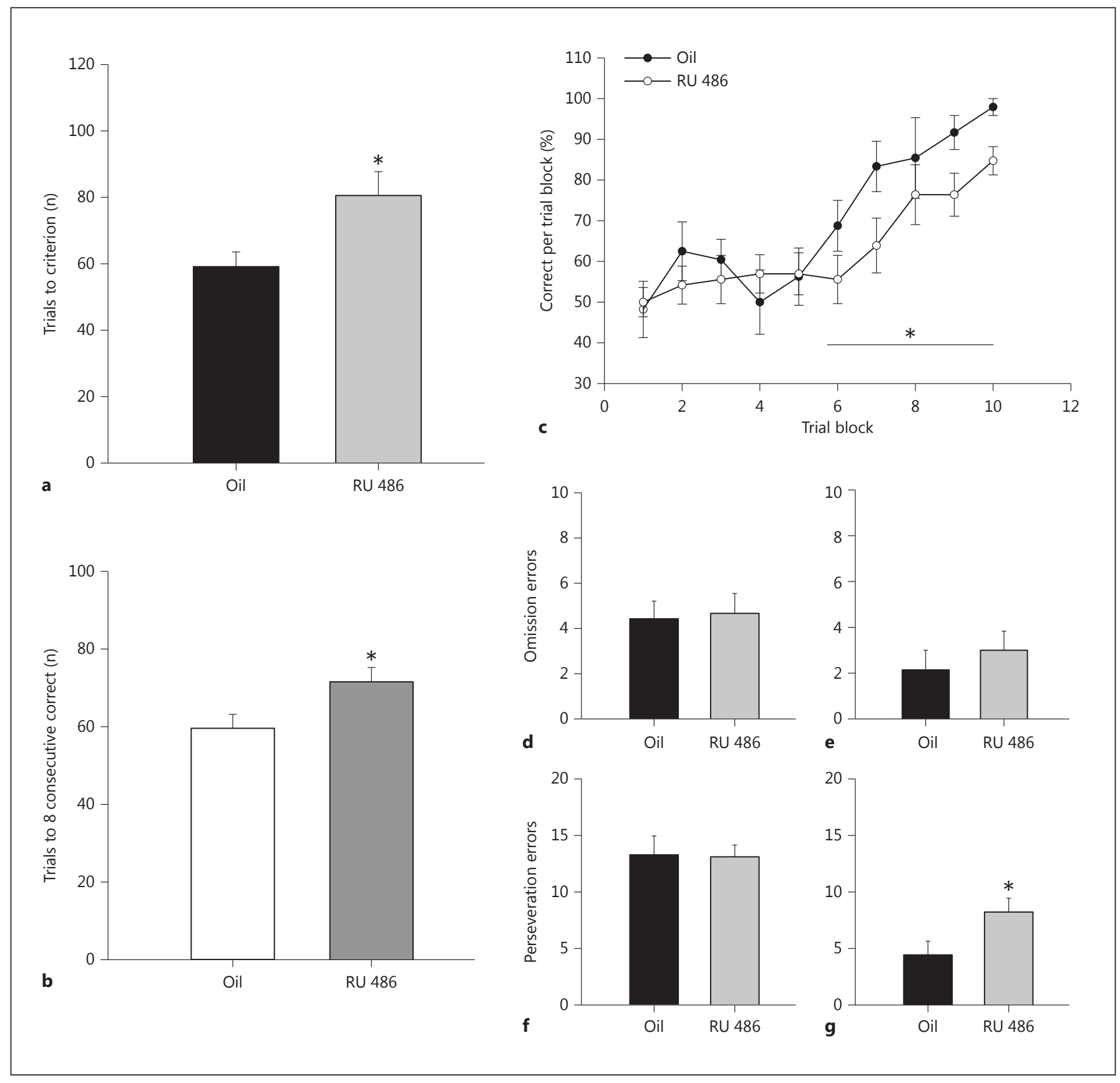

Fig. 7. Inhibition of $P R$ activity during neonatal life impairs cognitive flexibility and increases perseverative errors in adult rats. a, b RU 486-treated rats required a significantly greater number of trials to reach 8 consecutive correct responses in set 1 (a) and in set 2 (b) compared to controls. c Percent correct responses in set 2 following the rule change for trial blocks $1-10$ ( 8 trials each) in RU 486-treated rats or oil-treated controls. There was no significant difference in performance between the treatment groups in trial blocks 1-5. However, in trial blocks 6-10, RU 486-treated rats were slower to acquire the new rule (i.e. had significantly fewer correct responses) and never reached the performance of controls. d, e There was no effect of treatment on the number of omission errors (i.e. errors made using neither the first nor the new rule) in either trial blocks 1-5 (d) or 6-10 (e). f, g Both groups made a high number of perseverative errors (i.e. errors made using the first rule) in trial blocks 1-5 (f). RU 486-treated rats continued to make a significantly greater number of perseverative errors in trial blocks 6-10 compared to controls $(\mathbf{g})$. Data are presented as means \pm SEM. ${ }^{*} \mathrm{p}<0.05$. 
Fig. 8. Cognitive flexibility is impaired in PRKO mice. a There was no significant effect of genotype on the mean latency to find a visible platform (visible) or to learn the location of a hidden platform (hidden 1 and 2). However, PRKO mice had a significantly longer latency to find the hidden platform after it was moved to a new quadrant (switch 1), but they reduced their latency to the level of the controls during the second trial (switch 2), suggesting that PRKO mice were capable of learning the new location but were slower to make the change (i.e. reduced cognitive flexibility). b There was no significant difference in swim speed across all trials between PRKO and WT mice. c, d PRKO mice made a significantly greater number of perseveration errors (entering the quadrant in which the platform was previously hidden) on both switch 1 and switch 2. Data are presented as means \pm SEM. ${ }^{*} \mathrm{p}<0.05$.
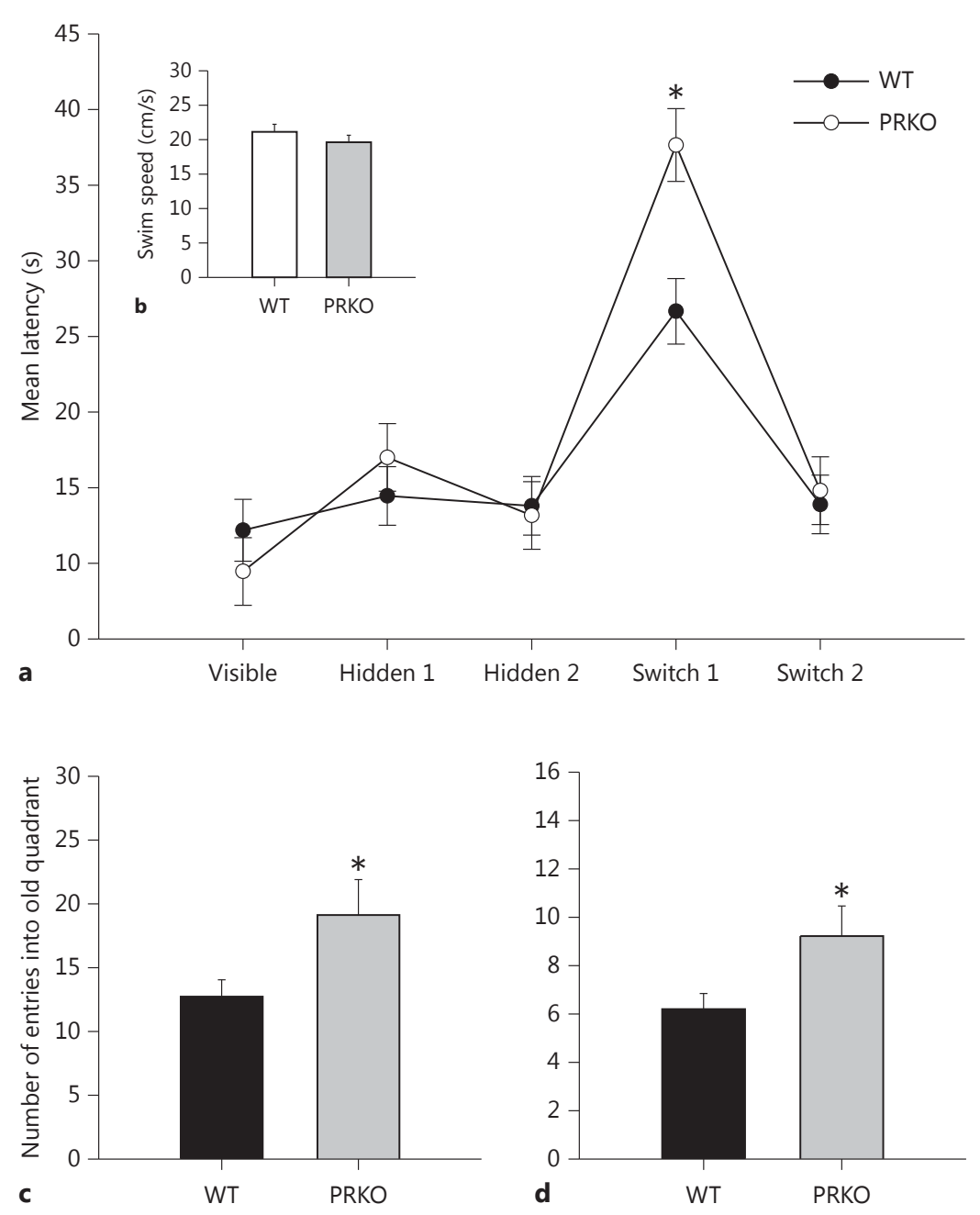

life plays a previously overlooked role in the normal development of the mesocortical dopaminergic pathway and in normal complex cognitive behaviors in adulthood. $\mathrm{PR}$ is transiently expressed during development in both the source cells and target cells of the mesocortical pathway. PR-ir is observed in the parabrachial and paranigral subregions of the VTA during the first 2 weeks of life, with peak levels of expression occurring just after birth, continuing through at least P14, but being absent by P28. The vast majority of PR-expressing cells in the neonatal VTA of rats are dopaminergic, coexpressing TH. Indeed, many of the VTA PR-ir cells project directly to the PL and IL mPFC. PR is also transiently expressed within layers II and III of the MPFC beginning at P6, with a peak in expression around $\mathrm{P} 10$, but being absent by $\mathrm{P} 30$. Inhibition of PR activity during neonatal life significantly reduced $\mathrm{TH}$-ir fiber density in layer II of the PL mPFC in preadolescent rats (with a similar trend in PRKO mice) and decreased TH-ir levels in the VTA of both rats and PRKO mice. Lastly, inhibition of PR activity during development altered behavioral inhibition/impulsivity in adult rats and impaired cognitive flexibility in rats and PRKO mice in adulthood.

To our knowledge, the present findings are the first to report the presence of steroid receptors in cortically projecting dopaminergic cells of the VTA during development, although these results are consistent with previous reports from our laboratory demonstrating developmentally transient expression of PR-ir in the VTA and substantia nigra, as well as in other areas of the midbrain and 
hindbrain [9]. In adulthood, androgen receptor and estrogen receptor- $\beta$, but not estrogen receptor- $\alpha$, were colocalized with TH in VTA $[44,45]$ and were found in VTA cells projecting to PFC [46]. However, the transient expression of PR the VTA during an important period of dopamine cell maturation [27] identifies PR as a potential contributor to the proper development of dopaminergic efferents from the midbrain.

Neonatal inhibition of PR with RU 486, while not altering the number of dopaminergic cells in the VTA, decreased relative total levels of $\mathrm{TH}$ protein, suggesting overall reduced rates of dopamine synthesis. The timing of peak PR expression in dopaminergic VTA cells during the first postnatal week coincides with transient alterations in the number of TH-ir neurons in the VTA [27]. Interestingly, in both rats and mice, a decrease in $\mathrm{TH}$ levels was only observed in adulthood but not at P25, suggesting that PR activity in early life might influence further developmental processes in the mesocortical pathway that occur during adolescence. This is consistent with findings that estradiol exposure on the day of birth altered adult levels of dopamine in the VTA as measured by HPLC [47] and with reports that in undifferentiated embryonic cultured stem cells, progesterone increased the number of TH-positive cells and virtually all cells induced to become dopaminergic expressed PR [16]. In addition, progesterone increased promoter activity in the $\mathrm{TH}$ gene in cells transfected with the gene for $\mathrm{PR}_{\mathrm{B}}$, suggesting that ligand-bound $\mathrm{PR}_{\mathrm{B}}$ can be a transcriptional activator of TH gene expression [48]. PR activity in the VTA during development may induce transient changes in $\mathrm{TH}$ gene expression, leading to long-term alterations in dopamine synthesis in the adult VTA.

PR was also transiently expressed in layers II and III of the $\mathrm{mPFC}$ during the period in which afferents arrive in the $\mathrm{mPFC}$ and form mature patterns of connectivity in superficial cortical layers, similar to the developmentally and anatomically specific pattern of PR expression in all other functional regions of the cortex [10, 11, 49]. RU 486 treatment neonatally decreased the density of TH-ir fibers in the PL mPFC at P25 but not in adulthood, suggesting that PR activity earlier in development may set the stage for subsequent maturation that occurs in the PFC during adolescence, potentially permanently altering subsequent dopaminergic activity. Indeed, previous work shows that neonatal progesterone administration increased the dopamine metabolites DOPAC and homovanillic acid in the adult PFC [17], indicating an increase in dopamine turnover.

PR and Mesocortical Development
There are several potential mechanisms by which PR activity might alter the 'attractiveness' of mPFC target cells to influence the development of mesocortical circuits. For example, it is generally accepted that the extension and branching of the dendritic arbor and the density of dendritic spines on target cells are integral to the process of synaptogenesis $[50,51]$, and steroid hormones can regulate dendritic structures in both the adult and the developing brain [52-55]. In developing pyramidal cells of the hippocampus, testosterone increased dendritic length and increased the number of dendritic branches [56]. In neonatal Purkinje cells, both progesterone and estradiol can promote dendritic outgrowth and increase the density of dendritic spines $[55,57,58]$. In developing cortical pyramidal cells, progesterone given to pregnant rats increased dendritic branching and increased the density of dendritic spines [59]. As another possibility, PR may regulate the expression of trophic factors in the developing cortex. Indeed, there is a wealth of evidence that progesterone and its metabolites can regulate brain-derived neurotrophic factor expression in numerous brain regions in adulthood [reviewed in 60], although little evidence exists regarding early development. However, in dissociated P3 cell cultures of the PFC, progesterone increased brain-derived neurotrophic factor expression, and this increase was attenuated by RU 486 and in PRKO mice [61]. PR regulation of the $\mathrm{MPFC}$ target cell phenotype might influence synaptogenesis amongst arriving afferents, thereby potentially altering the strength and spatial patterning of connectivity.

Consistent with alterations in the mesocortical dopamine circuitry, PR inhibition during neonatal life impaired complex cognitive behaviors that are dependent on dopaminergic activity in the mPFC $[31,62,63]$. First, RU 486 treatment during the first 2 weeks of life decreased behavioral inhibition and/or increased impulsivity. In a passive inhibitory avoidance task, RU 486-treated rats were quicker to enter the dark chamber compared to controls, despite having received an aversive foot shock in that chamber previously. Both groups were equally highly motivated to enter the dark chamber on the first trial, and RU 486-treated rats had a significantly longer latency to enter the dark chamber on the second trial compared to the first trial, suggesting that memory for the aversive stimuli was intact. Rather, the findings suggest that RU 486 treatment impaired the ability to inhibit a motivated response (i.e. increased impulsivity) even in light of negative consequences.

Neonatal RU 486 treatment also impaired cognitive flexibility and increased perseveration in the attentional

Neuroendocrinology 2016;103:207-222 219 
set-shifting task. RU 486-treated animals were slower than controls to make the shift to the new rule and made significantly more perseverative errors, in effect continuing to apply the old rule. Interestingly, RU 486-treated animals required more trials to reach the criterion of learning the initial rule, suggesting that PR expressed in the developing hippocampus [8] or the mesocortical pathway may play a role in adult working memory as well. Nonetheless, both groups were performing at equal levels by the end of testing on the first day and made equivalent errors using the first rule on the beginning of the second day, suggesting that RU 486 did not affect retention of the initial rule. RU 486 is a potent PR antagonist, but it also acts as an antagonist at glucocorticoid receptors, even if with lower affinity. However, glucocorticoid receptor expression is relatively low in the neonatal hippocampus and cortex [64, reviewed in 65], suggesting that the effects of RU 486 in the present studies were most likely attributable to inhibition of PR activity specifically. Additionally, PRKO mice showed a similar deficit in cognitive flexibility on an adapted water maze task and also made more perseverative errors compared to controls. These results provide a convergence of evidence, using both pharmacological and genetic approaches, suggesting that PR activity during development is important for the normal development of mPFC-dependent cognitive behaviors.

Interestingly, the deficits induced by developmental $\mathrm{PR}$ inhibition are in many ways similar to those seen in a variety of human behavioral disorders. Disruptions of normal development can lead to permanent alterations in mesocortical structure and function which can manifest in behavioral disorders such as attention deficit/hyperactivity disorder and schizophrenia [1-7], both of which are associated with deficits in cognitive flexibility and impaired impulse control. The present results implicate PR in the normal development of the circuits underlying these behaviors and raise the possibility that perturbations in the progesterone exposure or in the levels of PR expression during critical developmental windows may increase susceptibility to these disorders. Furthermore, these findings have implications for the use of synthetic progestins for the prevention of premature birth in at-risk pregnant women [reviewed in 66] and the potential effects on development of the fetal brain.

\section{Acknowledgements}

This work was supported by NSF grant IOS1050367 and NICHD grant HD07643001 to C.K.W.

\section{Disclosure Statement}

The authors declare no competing financial interests.

\section{References}

1 Goto Y, Grace AA: Alterations in medial prefrontal cortical activity and plasticity in rats with disruptions of cortical development. Biol Psychiatry 2006;60:1259-1267.

$\checkmark 2$ Floresco SB, Magyar O: Mesocortical dopamine modulation of executive functions: beyond working memory. Psychopharmacology 2006;188:567-585.

3 Sullivan RM, Brake WG: What the rodent prefrontal cortex can teach us about attention deficit/hyperactivity disorder: the critical role of early developmental events on prefrontal function. Behav Brain Res 2003;146:43-55.

4 Viggiano D, Vallone D, Ruocco LA, Sadile AG: Behavioural, pharmacological, morphofunctional molecular studies reveal a hyperfunctioning mesocortical dopamine system in an animal model of attention deficit and hyperactivity disorder. Neurosci Biobehav Rev 2003;27:683-689.
5 Arnsten AF, Li BM: Neurobiology of executive functions: catecholamine influences on prefrontal cortical functions. Biol Psychiatry 2005;57:1377-1384.

-6 Brennan AR, Arnsten AFT: Neuronal mechanisms underlying attention deficit hyperactivity disorder: the influence of arousal on prefrontal cortical function. Ann NY Acad Sci 2008;1129:236-245.

7 Prince J: Catecholamine dysfunction in attention deficit-hyperactivity disorder: an update. J Clin Psychopharmacol 2008;28(suppl 2):S39-S45.

8 Quadros PS, Pfau JL, Wagner CK: Distribution of progesterone receptor immunoreactivity in the fetal and neonatal rat forebrain. J Comp Neurol 2007;504:42-56.

-9 Quadros PS, Schlueter LJ, Wagner CK: Distribution of progesterone receptor immunoreactivity in the midbrain and hindbrain of postnatal rats. Dev Neurobiol 2008;68:13781390.
10 Lopez V, Wagner CK: Progestin receptor is transiently expressed perinatally in neurons of the rat isocortex. J Comp Neurol 2009;512: 124-139.

11 Jahagirdar V, Wagner CK: Ontogeny of progesterone receptor expression in the subplate of fetal and neonatal rat cortex. Cereb Cortex 2010;20:1046-1052.

12 Beyer C, Damm N, Brito V, Kuppers E: Developmental expression of progesterone receptor isoforms in the mouse midbrain. Dev Neurosci 2002;13:877-880.

13 De Brabander JM, Kramers JK, Uylings HBM: Layer-specific dendritic regression of pyramidal cells with aging in the human prefrontal cortex. Eur J Neurosci 1998;10:1261-1269.

14 Petanjek Z, Judas M, Kostovic I, Uylings HBM: Lifespan alterations of basal dendritic trees of pyramidal neurons in the human prefrontal cortex: a layer-specific pattern. Cereb Cortex 2008;18:915-929. 
15 Ernst M, Fudge JL: A developmental neurobiological model of motivated behavior: anatomy, connectivity and ontogeny of the triadic nodes. Neurosci Biobehav Rev 2009;33:367382.

16 Diaz NF, Guerra-Arraiza C, Diaz-Martinez NE, Salazar P, Molina-Hernandez A, Camacho-Arroyo I, Velasco I: Changes in the content of estrogen and progesterone receptors during differentiation of mouse embryonic stem cells to dopamine neurons. Brain Res Bull 2007;73:75-80.

17 Muneoka K, Kuwagata M, Ogawa T, Shioda $S$ : Sex-specific effects of early neonatal progesterone treatment on dopamine and serotonin metabolism in rat striatum and frontal cortex. Life Sci 2010;87:738-742.

18 Lydon J, DeMayo F, Funk C, Mani S, Hughes A, Montgomery C, Shyamala G, Conneely OM, O’Malley BW: Mice lacking progesterone receptor exhibit pleiotropic reproductive abnormalities. Genes Dev 1995;9:2266-2278.

19 Lonstein JS, Quadros PS, Wagner CK: Effects of neonatal RU486 on adult sexual, parental and fearful behaviors in rats. Behav Neurosci 2001;115:58-70.

-20 Quadros PS, Lopez V, De Vries GJ, Chung WC, Wagner CK: Progesterone receptors and the sexual differentiation of the medial preoptic nucleus. J Neurobiol 2002;51:24-32.

21 Traish AM, Wotiz HH: Monoclonal and polyclonal antibodies to human progesterone receptor peptide-(533-547) recognize a specific site in unactivated (8S) and activated (4S) progesterone receptor and distinguish between intact and proteolyzed receptors. Endocrinology 1990;127:1167-1175.

22 Tetel MJ, Jung S, Carbajo P, Ladtkow T, Skafar DF, Edwards DP: Hinge and amino-terminal sequences contribute to solution dimerization of human progesterone receptor. $\mathrm{Mol}$ Endocrinol 1997;11:1114-1128.

23 Karatsoreos IN, Bhagat S, Bloss EB, Morrison $\mathrm{JH}$, McEwen BS: Disruption of circadian clocks has ramifications for metabolism, brain and behavior. Proc Natl Acad Sci USA 2011;108:1657-1662.

-24 Gonzales KL, Tetel MJ, Wagner CK: Estrogen receptor (ER) $\beta$ modulates ERa responses to estrogens in the developing rat ventromedial nucleus of the hypothalamus. Endocrinology 2008; 149:4615-4621.

25 Heller A, Hutchens JO, Kirby ML, Karapas F, Fernandez C: Stereotaxic electrode placement in the neonatal rat. J Neurosci Methods 1979; 1:41-76.

26 Kalsbeek A, Voorn P, Buijs RM, Pool CW, Uylings HB: Development of the dopaminergic innervation in the prefrontal cortex of the rat. J Comp Neurol 1988;269:58-72.

-27 Lieb K, Anderson C, Lazarov N, Zienecker R, Urban I, Reisert I, Pilgrim C: Pre- and postnatal development of dopaminegic neuron numbers in the male and female mouse midbrain. Dev Brain Res 1996;94:37-43.
28 Park M, Kitahama K, Geffard M, Maeda T: Postnatal development of the dopaminergic neurons in the rat mesencephalon. Brain Dev 2000;22:S38-S44.

29 Prakash N, Wurst W: Development of dopaminergic neurons in the mammalian brain Cell Mol Life Sci 2006;63:197-206.

30 Paxinos G, Watson C: The Rat Brain in Stereotaxic Coordinates. San Diego, Academic Press, 1998.

31 Naneix F, Marchand AR, Di Scala D, Pape JR, Coutureau E: A role for medial prefrontal dopaminergic innervation in instrumental conditioning. J Neurosci 2009;29:6599-6606.

32 Van Eden CG, Uylings HBM: Cytoarchitectonic development of the prefrontal cortex in the rat. J Comp Neurol 1985;241:253-267.

33 Kritzer MF: Long term gonadectomy affects the density of tyrosine hydroxylase but not dopamine- $\beta$-hydroxylase, choline acetyl transferase or serotonin immunoreactive axons in the medial prefrontal cortices of adult male rats. Cereb Cortex 2003;13:282-296.

-34 Roozendaal B, McReynolds JR, Van der Zee EA, Lee S, McGaugh JL, McIntyre CK: Glucocorticoid effects on memory consolidation depend on functional interactions between the medial prefrontal cortex and basolateral amygdala. J Neurosci 2009;29:14299-14308.

35 McReynolds JR, Holloway-Erickson CM, Parmar TU, McIntyre CK: Corticosteroneinduced enhancement of memory and synaptic Arc protein in the medial prefrontal cortex. Neurobiol Learn Mem 2014;112:148157.

36 Yang FC, Liang KC: Interactions of the dorsal hippocampus, medial prefrontal cortex and nucleus accumbens in formation of fear memory: difference in inhibitory avoidance learning and contextual fear conditioning. Neurobiol Learn Mem 2014;112:186-194.

-37 Stefani MR, Moghaddam B: Rule learning and reward contingency are associated with dissociable patterns of dopamine activation in the rat prefrontal cortex, nucleus accumbens and dorsal striatum. J Neurosci 2006;26: 8810-8818.

38 Ragozzino ME, Detrick S, Kesner RP: Involvement of the prelimbic-infralimbic areas of the rodent prefrontal cortex in behavioral flexibility for place and response learning. J Neurosci 1999; 19:4585-4594.

39 Birrell JM, Brown VJ: Medial prefrontal cortex mediates perceptual attentional set-shifting in the rat. J Neurosci 2000;20:4320-4324.

40 Ragozzino ME, Hassert KJ, Minniti N, Kiang C: The contribution of the rat prelimbic-infralimbic areas to different forms of task switching. Behav Neurosci 2003;117:10541065 .

41 Floresco SB, Block AE, Tse MTL: Inactivation of the medial prefrontal cortex of the rat impairs strategy set-shifting, but not reversal learning, using a novel, automated procedure. Behav Brain Res 2008;190:85-96.
42 Rich EL, Shapiro M: Rat prefrontal cortical neurons selectively code strategy switches. J Neurosci 2009;29:7208-7219.

-43 Jahng JW, Ryu V, Yoo SB, Noh SJ, Kim JY, Lee $\mathrm{JH}$ : Mesolimbic dopaminergic activity responding to acute stress is blunted in adolescent rats that experienced neonatal maternal separation. Neuroscience 2010;171:144-152.

44 Kritzer MF: Selective colocalization of immunoreactivity for intracellular gonadal hormone receptors and tyrosine hydroxylase in the ventral tegmental area, substantia nigra and retrorubral fields in the rat. J Comp Neurol 1997;379:247-260.

45 Creutz LM, Kritzer MF: Mesostriatal and mesolimbic projections of midbrain neurons immunoreactive for estrogen receptor beta or androgen receptors in rats. J Comp Neurol 2004;476:348-362.

46 Kritzer MF, Creutz LM: Region and sex differences in constituent dopamine neurons and immunoreactivity for intracellular estrogen and androgen receptors in mesocortical projections in rats. J Neurosci 2008;28:95259535.

47 Cruz G, Riquelme R, Espinosa P, Jara P, Dagino-Subiabre A, Renard GM, Sotomayor-Zarate R: Neonatal exposure to estradiol valerate increases dopamine content in nigrostriatal pathway during adulthood in the rat. Horm Metab Res 2014;46:322-327.

48 Jensik PJ, Arbogast LA: Differential and interactive effects of ligand-bound progesterone receptor $\mathrm{A}$ and $\mathrm{B}$ isoforms on tyrosine hydroxylase promoter activity. J Neuroendocrinol 2011;23:915-925.

49 Willing J, Wagner CK: Sensorimotor development in neonatal progesterone receptor knockout mice. Dev Neurobiol 2014;74:1624.

50 Segal M, Murphy D: Estradiol induces formation of dendritic spines in hippocampal neurons: functional correlates. Horm Behav 2001;40:156-159.

51 Yuste R, Bonhoeffer T: Morphological changes in dendritic spines associated with longterm synaptic plasticity. Annu Rev Neurosci 2001;24:1071-1089.

52 Murphy DD, Segal M: Progesterone prevents estradiol-induced dendritic spine formation in cultured hippocampal neurons. Neuroendocrinology 2000;72:133-143.

53 Woolley CS: Effects of oestradiol on hippocampal circuitry. Novartis Found Symp 2000; 230:173-180, discussion 181-187.

54 Mong JA, Roberts RC, Kelly JJ, McCarthy MM: Gonadal steroids reduce the density of axospinous synapses in the developing rat arcuate nucleus: an electron microscopy analysis. J Comp Neurol 2001;432:259-267.

55 Sakamoto H, Ukena K, Tsutsui K: Effects of progesterone synthesized de novo in the developing Purkinje cell on its dendritic growth and synaptogenesis. J Neurosci 2001;21: 6221-6232. 
56 Isgor C, Sengelaub DR: Effects of neonatal gonadal steroids on adult CA3 pyramidal neuron dendritic morphology and spatial memory in rats. J Neurobiol 2003;55:179-190.

-57 Sakamoto H, Ukena K, Tsutsui K: Dendritic spine formation in response to progesterone synthesized de novo in the developing Purkinje cell in rats. Neurosci Lett 2002;322:111115.

58 Sakamoto H, Mezaki Y, Shikimi H, Ukena K, Tsutsui K: Dendritic growth and spine formation in response to estrogen in the developing Purkinje cell. Endocrinology 2003;144:44664477.

59 Menzies KD, Drysdale DB, Waite PM: Effects of prenatal progesterone on the development of pyramidal cells in rat cerebral cortex. Exp Neurol 1982;77:654-667.
60 Pluchino N, Russo M, Santoro AN, Litta P, Cela V, Genazzani AR: Steroid hormones and BDNF. Neuroscience 2013;239:271-279.

61 Jodhka PK, Kaur P, Underwood W, Lydon JP, Singh M: The differences in neuroprotective efficacy of progesterone and medroxyprogesterone acetate correlate with their effects on brain-derived neurotrophic factor expression. Endocrinology 2009;150:3162-3168.

62 Mello E, Souza T, Vianna MR, Rodrigues C, Quevedo J, Moleta BA, Izquierdo I: Involvement of the medial precentral prefrontal cortex in memory consolidation for inhibitory avoidance learning in rats. Pharmacol Biochem Behav 2000;66:615-622.
63 Kritzer MF, Brewer A, Montalmant F, Davenport M, Robinson JK: Effects of gonadectomy and hormone replacement on operant tasks measuring prefrontal cortical function in adult male rats. Horm Behav 2007;51:183194.

64 Ordya NE, Galeeva AY, Pivina SG: Expression of glucocorticoid receptor in the brain of rats during postnatal ontogeny. Bull Exp Biol Med 2008;146:176-179.

65 Pryce CR: Postnatal ontogeny of expression of the corticosteroid receptor genes in mammalian brains: inter-species and intra-species differences. Brain Res Rev 2008;57:596-605.

66 Schmouder VM, Prescott GM, Franco A, FanHavard P: The rebirth of progesterone in the prevention of preterm labor. Ann Pharmacother 2013;47:527-536. 